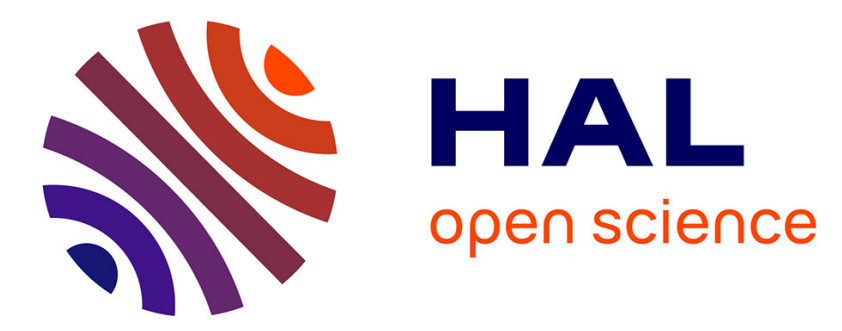

\title{
Modeling of the oxidation of large alkenes at low temperature
}

S. Touchard, R. Fournet, P.A. Glaude, V. Warth, F. Battin-Leclerc, G. Vanhove, M. Ribaucour, R. Minetti

\section{- To cite this version:}

S. Touchard, R. Fournet, P.A. Glaude, V. Warth, F. Battin-Leclerc, et al.. Modeling of the oxidation of large alkenes at low temperature. Proceedings of the Combustion Institute, 2005, 30 (1), pp.1073 1081. 10.1016/j.proci.2004.07.004 . hal-01738424

\section{HAL Id: hal-01738424 \\ https://hal.science/hal-01738424}

Submitted on 14 Sep 2020

HAL is a multi-disciplinary open access archive for the deposit and dissemination of scientific research documents, whether they are published or not. The documents may come from teaching and research institutions in France or abroad, or from public or private research centers.
L'archive ouverte pluridisciplinaire HAL, est destinée au dépôt et à la diffusion de documents scientifiques de niveau recherche, publiés ou non, émanant des établissements d'enseignement et de recherche français ou étrangers, des laboratoires publics ou privés. 


\section{MODELING OF THE OXIDATION OF LARGE ALKENES AT LOW TEMPERATURE}

S. TOUCHARD ${ }^{1}$, R. FOURNET ${ }^{1}$, P.A. GLAUDE ${ }^{*}$, V. WARTH ${ }^{1}$, F. BATTIN-LECLERC ${ }^{*}$, G. VANHOVE 2 , M. RIBAUCOUR ${ }^{2}$, R. MINETTI ${ }^{2}$ ${ }^{1}$ Département de Chimie-Physique des Réactions, UMR n7630 CNRS, INPL-ENSIC, 1 rue Grandville, BP 451, 54001 NANCY Cedex, France

${ }^{2}$ Physico-Chimie des processus de Combustion et de l'Atmosphère (PC2A), UMR n 8522 CNRS, Université des Sciences et Technologies de Lille, Bâtiment C11 59655 Villeneuve d'Ascq Cedex (France)

\section{Colloquium : Reaction Kinetics}

Short running title : Low-temperature oxidation of alkenes

\section{Total number of words : 5955}

\footnotetext{
* Corresponding author : Tel : 33383175125 - Fax : 33383378120

E-Mail : Frederique.Battin-Leclerc@ensic.inpl-nancy.fr
} 


\section{Details of words count}

Text $=3676$

Equations : 7 x 4 X7.6 $=\mathbf{2 1 3}$

References : $(21+2) \times 2,3 \times 7.6=\mathbf{4 0 2}$

\section{Figures :}

Figure 1: Count $=(7+(85 / 67) \times 67) \times 2.2+16=218$

Figure 2: Count $=(7+(65 / 67) \times 67) \times 2.2+33=191$

Figure $3:$ Count $=(7+(80 / 67) \times 67) \times 2.2+52=243$

Figure $4:$ Count $=(7+(70 / 67) \times 67) \times 2.2+12=181$

Figure $5:$ Count $=(7+(80 / 67) \times 67) \times 2.2+16=195$

Figure $6:$ Count $=(7+(110 / 220) \times 140) \times 4.4+38=376$

TOTAL FIGURES $=1400$

Table $1:$ Count $=130 \times 2.2=\mathbf{2 8 6}$

\section{TOTAL $=5955$}




\section{ABSTRACT}

This paper presents new kinetic mechanisms for the oxidation of 1-pentene and 1-hexene at low temperature, the development of which has required important improvements of the kinetic rules used by the system EXGAS, developed in our laboratory for the automatic generation of mechanisms. This paper details the changes or additions, which were needed in the definition of the specific generic reactions involving alkenes and their free radicals, as well as for the correlations to estimate the related rate constants. Tests have been performed to check that these improvements still allow good simulations in the case of propene. New mechanisms for the oxidation of 1-pentene and 1-hexene at low temperature have been thus generated and validated using experimental data obtained in a rapid compression machine between 600 and $900 \mathrm{~K}$. The mechanism for the oxidation of 1-pentene has also been tested in a plug flow reactor between $654 \mathrm{~K}$ and $716 \mathrm{~K}$. Results reveal an acceptable agreement between simulated and experimental data for auto-ignition delays and for the products distribution. The analysis of mechanisms has permitted to show the importance of new reaction pathways specific to long chain alkenes. This study confirms the great role played by the reaction of addition of small radicals on the double bond and by the specific reactivity of the allylic radical for the auto-ignition delays. It has also underlined the important role played by the reaction of allylic and alkenyl radicals with $\mathrm{O}_{2}$ giving dienes and has allowed us to refine the kinetic value for these generic reactions.

Keywords : Alkenes, 1-pentene, 1-hexene, oxidation, auto-ignition, modeling. 


\section{INTRODUCTION}

Despite that alkenes are included in LPGs (up to $40 \%$ ) and in gasoline (up to $20 \%$ ) and are primary products formed during the oxidation of alkanes, which play a significant role in combustion kinetics, there are very few kinetic modeling of the oxidation of alkenes containing more than four atoms of carbon.

In order to better understand the combustion chemistry in an engine, it is necessary to model the oxidation of larger alkenes more representative of those included in fuels, such as 1-pentene included in gasoline up to $1 \%$ with a research octane number of 90.9 or 1-hexene included in gasoline up to $0.3 \%$ with a research octane number of 76.4 . We have attempted to achieve this purpose by using the system EXGAS, which had been developed in our laboratory for the automatic generation of mechanisms and which was recently improved in order to model the oxidation of alkenes and tested in the case of the oxidation of propene [1,2] and 1-butene [2].

The oxidation of 1-pentene has been experimentally studied by Ribaucour et al. [3] in a rapid compression machine between 600 and $900 \mathrm{~K}$ and by Prabhu et al. [4] in a plug flow reactor between 654 and $716 \mathrm{~K}$. Ribaucour et al. [3] have proposed a detailed mechanism able to reproduce their measured ignition delays, but which did not contain all the possible reactions, which could be envisaged for the oxidation of this alkene. For instance, the abstractions of alkylic $\mathrm{H}$-atoms, the isomerizations of the peroxyradicals deriving from the successive additions of hydroxyl radicals and oxygen molecules or the formations of unsaturated cycloethers have not been considered. 
Experimental results for the auto-ignition of 1-hexene have been recently obtained by Vanhove et al. [5] in a rapid compression machine between 600 and $900 \mathrm{~K}$, but have not yet been modeled.

The purpose of the present paper is to describe the new kinetic rules, which have been implemented in the EXGAS system to obtain mechanisms for the oxidation of large alkenes. After checking that these rules have no negative effects on our simulations of the oxidation of propene [1], this new version of EXGAS has been used to generate kinetic models for the oxidation of 1-pentene and for that of 1-hexene. These mechanisms have been used, without any a posteriori fitting, to reproduce the results of three experimental studies, which were obtained in the low and negative temperature coefficient regions. In order to better understand the reactions of importance for the oxidation of such large alkenes, an analysis of the obtained mechanisms are also presented here.

\section{DESCRIPTION OF THE MODEL}

The proposed models have been generated using the EXGAS system, in which some specific improvements have been made in order to correctly model the oxidation of large alkenes at low temperature.

\section{General features about the EXGAS system}

Because it has already been extensively described [1-2, 6-8], only a summary of the main 
features of EXGAS is given here. The system provides reaction mechanisms made of three parts:

- $\mathrm{A} \mathrm{C}_{0}-\mathrm{C}_{2}$ reaction base, including all the reactions involving radicals or molecules containing less than three carbon atoms [9].

- A comprehensive primary mechanism, where the only molecular reactants considered are the initial organic compounds and oxygen.

Figure 1 summarizes the different types of generic reactions, which are taken into account in the primary mechanism of the oxidation of alkenes, and the structure of the algorithm, which is used for the generation and which ensures the comprehensiveness of the mechanisms. Previous papers $[1,2]$ describe in details these generic reactions and the related kinetic parameters.

- A lumped secondary mechanism, containing reactions consuming the molecular products of the primary mechanism, which do not react in the reaction bases.

Thermochemical data for molecules or radicals are automatically calculated and stored as 14 polynomial coefficients, according to the CHEMKIN II formalism [10]. These data are computed using the THERGAS software [11], based on group and bond additivity methods proposed by Benson [12].

Kinetic data are either calculated using the KINGAS software [13] based on thermochemical kinetics methods [12] or estimated through quantitative structure-reactivity relationships [1-2, 6-8]. 
Specific improvements made in order to model the oxidation of large alkenes

We present here only the generic reactions or kinetic parameters, which have been modified compared to what was previously described to model the oxidation of propene [1] and butene [2].

\section{$\checkmark$ Retro-ene reactions}

Alkenes larger than propene and butene can decompose via a retro-ene mechanism with a preexponential factor of $4.10^{12} \mathrm{~s}^{-1}$ and an activation energy of $236 \mathrm{~kJ} / \mathrm{mol}$ based on the results of Richard et al. [14]. A retro-ene reaction is a 1,5-hydrogen shift reaction concerted with dissociation. In the case of 1-hexene, it leads to two propene molecules :

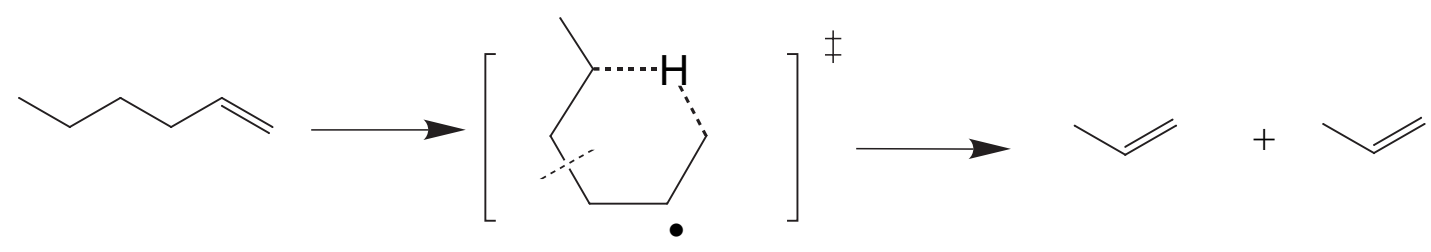

Propene and ethylene are obtained from 1-pentene.

\section{- Reactions of resonance stabilized radicals}

The generic reactions have been considered for the two possible forms of every resonance stabilized radicals. For instance, the addition to oxygen of the ethylallyl radicals can lead to two different peroxy radicals : 


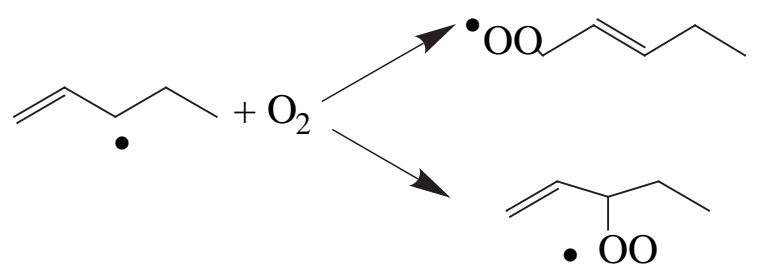

- Isomerizations

The activation energy is set equal to the sum of the activation energy for $\mathrm{H}$-abstraction from the substrate by analogous radicals and the strain energy of the saturated or unsaturated cyclic transition state. The activation energy of the abstraction of a hydrogen atom is considered 8.4 $\mathrm{kJ} / \mathrm{mol}$ lower, from an atom of carbon linked to an atom of oxygen, than from an atom of carbon linked to no oxygen atom. The activation energy of the abstraction of a hydrogen atom by allylic radicals is considered $41 \mathrm{~kJ} / \mathrm{mol}$ higher than by alkyl radicals. Strain energies of the cyclic transition states containing two oxygen atoms and a double bond were taken equal to $63 \mathrm{~kJ} / \mathrm{mol}$ (for a five membered ring), $41 \mathrm{~kJ} / \mathrm{mol}$ (for a six membered ring), $4 \mathrm{~kJ} / \mathrm{mol}$ (for a seven membered ring) and $0 \mathrm{~kJ} / \mathrm{mol}$ (for a height membered ring). These strain energies were deduced from the values proposed for saturated cyclic transition states containing two oxygen atoms [8] and from the differences of ring correction between saturated and unsaturated cycles proposed by Benson [12].

\section{- Decompositions to give cyclic ethers}

The application to the case of alkenes of the generic reaction of formation of cyclic ethers, which is usually considered in alkanes oxidation mechanisms, leads to the formation of cyclic ethers bearing an alcohol function or an unsaturated chain or including a double bond in the ring, 
as shown in the example below:

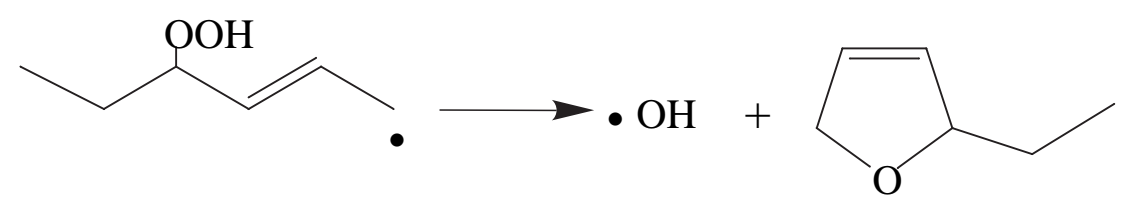

We consider the formations of these ethers with rate parameters adapted to take into account the differences with the cyclic ethers formed during the oxidation of alkanes. The rate constants for the formation of saturated cycles are those presented previously [6-8]. A-factors for the formation of unsaturated cycles were estimated from those of saturated cycles by considering that an unsaturated free radical contains one internal rotation less than the corresponding saturated radical and can then lose one rotation less to give the transition state. Activation energies were estimated from the differences of enthalpies of formation between cycloalkanes and cycloalkenes [12]. While in the case of propene, only one unsaturated four membered ring can be formed (with an activation energy of $80 \mathrm{~kJ} / \mathrm{mol}$ ), unsaturated five membered ring (with an activation energy of $25 \mathrm{~kJ} / \mathrm{mol}$ ) and six membered ring (with an activation energy of $13 \mathrm{~kJ} / \mathrm{mol}$ ) can be obtained for longer alkenes.

\section{- Oxidations involving the abstraction of an allylic hydrogen atom}

An example of this reaction is :

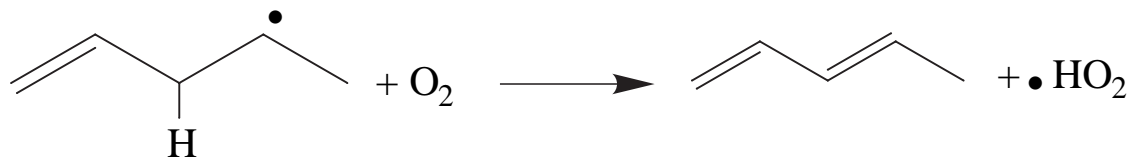

In our previous study [2], the rate parameters for this type of reaction, which was not possible in the case of propene, were deduced from those of alkylic H-atoms (A equal to $2.3 \times 10^{11}$ 
$\mathrm{cm}^{3} \cdot \mathrm{mol}^{-1} \cdot \mathrm{s}^{-1}$ for the abstraction of a primary H-atom, A equal to $7.9 \times 10^{11} \mathrm{~cm}^{3} \cdot \mathrm{mol}^{-1} \cdot \mathrm{s}^{-1}$ for the abstraction of a secondary $\mathrm{H}$-atom, Ea equal to $20 \mathrm{~kJ} / \mathrm{mol}[6])$ with an activation energy 10 $\mathrm{kJ} / \mathrm{mol}$ lower. But, this estimation omitted the fact that the formation of the conjugated diene from a non resonance stabilized radical involved a loss of an additional free rotation compared to the formation of an alkene from an alkyl radical. To take into account this effect, an A-factor divided by 6, compared to that of alkyl radicals [6] is now proposed for this generic reaction. This change has only a limited influence on our previous results of the oxidation of 1-butene at high temperature.

\section{- Oxidations involving the abstraction of a hydrogen atom next to an allylic radical center}

An example of this reaction is :

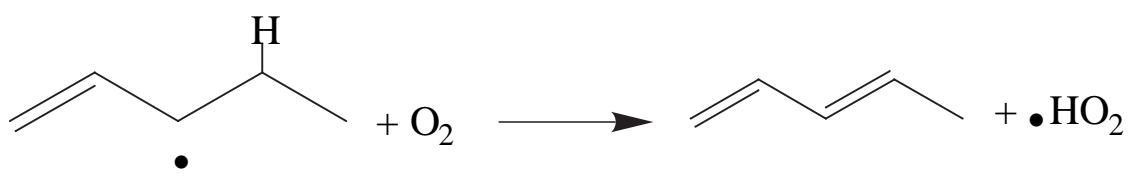

This type of reaction was also not possible in the case of propene and of low importance in the case of the oxidation of 1-butene at high temperature. In our previous study [1], the rate parameters used for this generic reaction were deduced from those used for alkyl radicals [1] (i.e. A equal to $2.3 \times 10^{11} \mathrm{~cm}^{3} \cdot \mathrm{mol}^{-1} \cdot \mathrm{s}^{-1}$ for the abstraction of a primary $\mathrm{H}$-atom, A equal to $7.9 \times 10^{11}$ $\mathrm{cm}^{3} \cdot \mathrm{mol}^{-1} \cdot \mathrm{s}^{-1}$ for the abstraction of a secondary H-atom, E equal to $41 \mathrm{~kJ} / \mathrm{mol}$ ) to agree with a rate constant proposed by Baldwin and Walker [15] for the formation of 1,3-pentadiene from ethylallyl radicals. These authors have experimentally measured the ratio between the concentration of 1,3-pentadiene and that of 1,3-butadiene at $753 \mathrm{~K}$. They have derived, from this 
measurement; the ratio $\left(\mathrm{k}_{1} / \mathrm{k}_{2}\right)$ between the rate constant of the oxidation of allylic radicals to 1,3-pentadiene $\left(\mathrm{k}_{1}\right)$ and the rate constant of the decomposition of allylic radicals to 1,3-butadiene and methyl radicals $\left(\mathrm{k}_{2}\right)$. Taking into account the experimental value measured by Baldwin and Walker for $\mathrm{k}_{1} / \mathrm{k}_{2}$ (i.e. $0.59 \mathrm{~m}^{3} \cdot \mathrm{mol}^{-1}$ ), but using for $\mathrm{k}_{2}$ the value more recently proposed by Perrin et al. [16] $\left(\mathrm{k}_{2}=1.6 \times 10^{13} \exp (-160 / \mathrm{RT}) \mathrm{s}^{-1}\right.$, throughout this paper $\mathrm{R}$ is the gas constant expressed in $\mathrm{kJ} \cdot \mathrm{mol}^{-1} \cdot \mathrm{K}^{-1}$ ) and considering the same A-factor as in the case of alkyl radicals, a new value of the activation energy of this type of reaction has been obtained (i.e. $65 \mathrm{~kJ} / \mathrm{mol}$ ).

\section{- Oxidations involving the abstraction of a hydroxylic hydrogen atom}

An example of this reaction is :

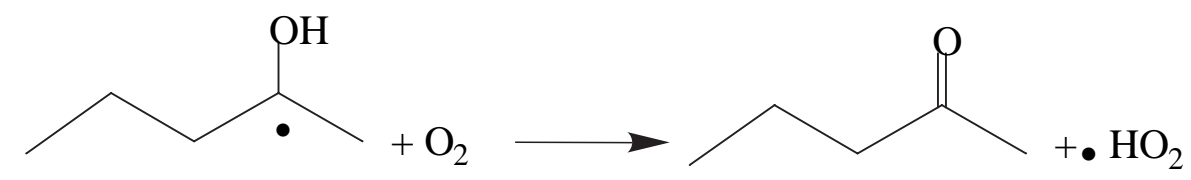

The formation of carbon atoms bearing a hydroxylic function and a radical center are more frequent in the case of 1-pentene, than for propene, due to the fact that isomerizations are easier in long chain alkenes. We have then added this new generic reaction. Moyoshi et al. [17] have measured the rate constant of this reaction at room temperature for several hydroxyalkyl radicals. These results show that, the rate constant is around 10 time higher than that of the oxidation of a non-substituted alkyl radical for the formation of an aldehyde ; while the rate constant is similar to that of the oxidation of a non-substituted alkyl radical for the formation of a ketone. According to the rate parameters used for the oxidation of non-substituted alkyl radical [6], an activation energy of $20 \mathrm{~kJ} / \mathrm{mol}$ and pre-exponential factor of $7.9 \times 10^{12} \mathrm{~cm}^{3} \cdot \mathrm{mol}^{-1} \cdot \mathrm{s}^{-1}$ for the 
formation of aldehydes and of $7.9 \times 10^{11} \mathrm{~cm}^{3} \cdot \mathrm{mol}^{-1} \cdot \mathrm{s}^{-1}$ for the formation of ketones have been used.

\section{- Cyclizations of alkenyl radicals}

In the case of long chain alkenes, the possible cyclisation of alkenyl radicals, as shown in the following example, needs to be taken into account.
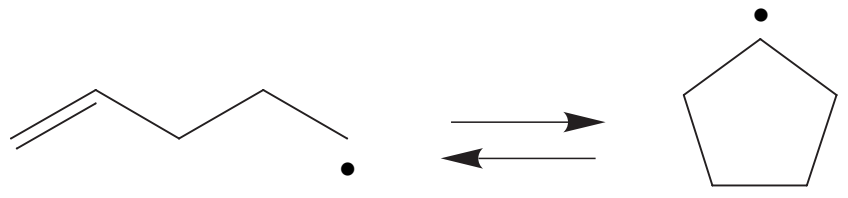

An A-factor of $1.4 \times 10^{11} \mathrm{~s}^{-1}$ and an activation energy of $\mathrm{E}=68 \mathrm{~kJ} \cdot \mathrm{mol}^{-1}$ have been taken from Gierczak et al. [18].

Checking for the modeling of the oxidation of propene

A new mechanism for the oxidation of propene has been generated taking into account the improvements previously described. Figure 2 shows a comparison between computed and experimental consumption of propene in the conditions of the study of Wilk et al. (a static reactor at 580 to $740 \mathrm{~K}$, equivalence ratios $(\Phi)$ equal to 0.8 and a pressure of $79 \mathrm{kPa})$ [1,19]. In this graph, as in all the figures presented hereafter, the points refer to experimental observations and the curves come from simulations.

Figure 2 shows that a globally correct agreement is still obtained. The modified mechanism leads to slightly better results at 678 and $715 \mathrm{~K}$ than the previous model [1], which gave better 
simulations at $626 \mathrm{~K}$.

Sensitivity analyses show that the oxidations involving the abstraction of a hydroxylic hydrogen atom have some effects on the results obtained at $626 \mathrm{~K}$.

\section{COMPARISON BETWEEN SIMULATIONS AND EXPERIMENTS}

The full kinetic mechanisms used, which include 3385 reactions involving 837 species for 1-pentene and 4526 reactions involving 1250 species for 1-hexene, are available on request. Simulations have been performed using the SENKIN software of CHEMKIN II [10] modified in order to consider overall heat loss to the walls of the vessel.

\section{Modelling of the oxidation of 1-pentene in a rapid compression machine [3]}

Ribaucour et al. [3] have measured auto-ignition delays and the distribution of products in a rapid compression machine for mixtures 1-pentene / oxygen / argon / nitrogen at temperatures after compression from 600 to $900 \mathrm{~K}$, pressures from 6.9 to 8.3 bar and a fuel equivalence ratio of 1 .

Figure 3 and Table 1 present a comparison between simulations and experimental results. Temperature is that calculated at the end of the compression based on a core gas model [3] and can be considered as the maximum temperature reached in the combustion chamber.

Figure 3 shows that a correct agreement is obtained both for cool flame and auto-ignition 
delays.

The model reproduces also the major trends of the distribution of products, even if discrepancies up to a factor 4 can be observed, certainly due to the important gradients of temperature, which are observed inside the combustion chamber of a rapid compression machine. Nevertheless, it is worth noting that the presence of unsaturated ethers or of ethers bearing an alcohol function is predicted by the model, but not shown in the present experimental analyses. While the selectivity of carbon monoxide is underpredicted by the model, simulations shows that formaldehyde is an important product, which has not been analyzed here.

\section{Modelling of the oxidation of 1-pentene in a plug flow reactor [4]}

Prabhu et al. [4] have studied the slow oxidation of 1-pentene in a plug flow reactor between 654 and $716 \mathrm{~K}$, at 8 atm and an equivalence ratio of 0.4. Figure 4 presents a comparison between the computed and experimental fuel consumption as a function of residence time at three fixed inlet temperatures, 654, 676 and $716 \mathrm{~K}$. As usual for modelling plug flow reactors, in which the zero time is not well defined, the simulated curves have been shifted to match correctly the experiments at $50 \%$ conversion.

Figure 4 shows that our model is able to satisfactorily reproduce the evolution of the consumption of 1-pentene as a function of residence time, and especially the negative temperature coefficient, which appears between 676 and $716 \mathrm{~K}$. 
Modelling of the oxidation of 1-hexene in a rapid compression machine [5]

Vanhove et al. [5] have measured auto-ignition delays in a rapid compression for mixtures 1-hexene / oxygen / argon / nitrogen / carbon dioxide at temperatures after compression from 615 to $850 \mathrm{~K}$, pressures from 6.8 to 10.9 bar and a fuel equivalence ratio of 1 .

Figure 5 shows that a correct agreement between modelling and experiments is obtained for auto-ignition delays. Simulations reproduce well the fact that 1-hexene is more reactive than 1-pentene, as indicated by the difference in octane numbers.

It is worth noting that preliminary products analyses have indicated the formation of ethers bearing an unsaturated chain, such 2-vinyl-tetrahydrofurane or including a double bond in the ring, such as 2-ethyl-2,5-dihydrofurane, which are predicted by our mechanism.

\section{ANALYSIS OF THE MECHANISMS}

For the shortness of the paper, we detail here only the analysis for the mechanism of 1-pentene in the conditions of the rapid compression machine and we discuss thereafter just the main differences appearing in the case of 1-hexene. 
Analysis of the mechanism of the oxidation of 1-pentene in a rapid compression machine

Fig. 6 presents an analysis of fluxes at $800 \mathrm{~K}$ in the conditions of Fig. 3 for $20 \%$ conversion of 1-pentene. Besides less than $1 \%$ of reactant reacting with $\cdot \mathrm{HO}_{2}$ to give 2-propyloxirane and $4 \%$ reacting by addition of hydrogen atoms to the double bond to give pentanyl radicals, the main reactions consuming 1-pentene are the following :

\section{- The additions of $\bullet \mathrm{OH}(33 \%$ of the consumption of 1-pentene)}

This channel and subsequent isomerizations lead to different isomers of $\bullet \mathrm{C}_{5} \mathrm{H}_{10} \mathrm{OH}$ radicals, which react mainly by oxidation to produce pentanal and by addition to oxygen to produce $\mathrm{C}_{5} \mathrm{H}_{10} \mathrm{OHOO} \cdot$. These peroxy radicals lead mainly to the formation of formaldehyde, butanal and $\cdot \mathrm{OH}$, due to isomerizations/decompositions, (Waddington's mechanism [1, 21]) or to hydroxyhydroperoxyalkyl radicals, which lead ultimately to the production of ketohydroperoxydes or of cyclic ethers bearing an alcohol function. 
- Metatheses involving $\bullet \mathrm{OH}$ radicals giving alkylic radicals $(26 \%$ of the consumption of

1-pentene)

These pathways lead to 1-penten-4-yl and 1-penten-5-yl radicals. 1-penten-5-yl radicals react mainly by $\beta$-scission decomposition to form ethylene and allyl radicals. 1-penten-4-yl radicals can react by addition to oxygen and lead ultimately to ketohydroperoxides and to unsaturated cyclic ethers. Another pathway leads to the formation of 1,3-pentadiene by an oxidation involving the abstraction of an allylic hydrogen atom. This pathway has an important effect on the reactivity in a rapid compression machine. Figure 3 presents the ignition delays curve simulated with a mechanism, in which the rate constant of this generic reaction has been multiplied by a factor 10 (modified simulation 1) and shows the important inhibiting effect of this reaction and then the influence of the related rate constant.

Metatheses involving $\bullet \mathrm{OH}$ radicals yielding allylic radicals $(36 \%$ of the consumption of

\section{1-pentene)}

Two resonance stabilized radicals are rapidly obtained, the ethylallyl radical and its isomer (2-hexen-4-yl, which is obtained by 1,4 isomerization from 2-hexen-1-yl, the mesomer form of ethylallyl). These radicals can react by combination with $\bullet \mathrm{HO}_{2}$ radicals to give hydroperoxides, which can decompose by breaking the $\mathrm{O}-\mathrm{OH}$ bond and produce unsaturated radicals, such butenyl radicals, which can lead to 1,3-butadiene, or unsaturated ketones or aldehyde, such as 2butenal or acroleine. They can also react by addition to oxygen and lead to the formation of 
propanal by internal addition or of unsaturated cyclic ethers, such as 2-methyl-2,5dihydrofurane.

The oxidation involving the abstraction of a hydrogen atom next to the allylic radical center has also an important kinetic effect, despite it corresponds to a low flow rate of consumption of ethylallyl radicals (around 1\% of the radicals consumption). Figure 3 presents the ignition delays curve simulated with a mechanism, in which the rate constant of this generic reaction has been multiplied by a factor 10 (modified simulation 2) and illustrates the inhibiting effect of this type of reaction.

Main differences between the mechanisms of the oxidation of 1-pentene and that of 1-hexene in a rapid compression machine

An analysis of fluxes performed for 1-hexene, in the same conditions as those for 1-pentene, would lead to a scheme very similar to that of figure 6. Nevertheless, differences can be observed in the fluxes of consumption of reactant. The additions of $\bullet \mathrm{OH}$ account for $28 \%$ (33\% for 1-pentene), allylic metathesis for $27 \%$ (36\% for 1-pentene) and alkylic metatheses for $35 \%$ (26\% for 1-pentene). This higher importance of alkylic metatheses certainly explains partly the difference of reactivity between these two compounds.

Moreover, the additions to oxygen of radicals 1-hexen-4-yl are favoured compared to the case of 1-penten-4-yl radicals, because the isomerizations of the obtained peroxy radicals are easier through a 6-members ring transition state. The oxidations of these radicals are then less 
important, that favours also the reactivity of 1-hexene, since these reactions have a strong inhibiting effect, as shown previously.

The formation of 2-ethyl-2,5-dihydrofurane, the main cyclic ether including a double bond in the ring, derives mainly from the addition to oxygen of 2-hexen-4-yl, obtained by isomerization from propylallyl radicals. The production of 2-vinyl-tetrahydrofurane, the main cyclic ether bearing an unsaturated chain, derives from the addition to oxygen, followed by an isomerization, of 1-hexen-5-yl radicals, as proposed by Vanhove et al. [5].

\section{CONCLUSION}

The oxidation of 1-pentene and of 1-hexene at low temperature has been modeled with a comprehensive mechanism automatically generated using the system EXGAS, in which the kinetic rules have been revisited to take into account reactions and rate constants specific to large alkenes. Tests have been performed to check that these improvements still allow good simulations in the case of propene.

The new mechanisms for the oxidation of 1-pentene and of 1-hexene have been used to model experimental results obtained in a rapid compression machine $[3,5]$ and in a plug flow reactor [4]. For 1-pentene, results in a rapid compression machine included both ignition delays and products distribution, while in the case of 1-hexene only ignition delays were available. But, the mechanism presented here is to our knowledge the first attempt to model the oxidation of 1-hexene at low temperature. 
Despite the fact that the kinetic parameters from the literature were not adjusted in order to improve the fit between the computed and experimental results, the agreement is generally correct, both for the shape of the curves and the position of the characteristic points of curves, such as minimum, maximum and inflexion points. It can therefore be concluded that, due to the systematic method used to generate the mechanism, no significant reactions were omitted and no strongly erroneous kinetic parameters were chosen.

Sensitivity analyses for the mechanism of the oxidation of 1-pentene have shown the importance of the formation of diene involving the abstraction of a hydrogen atom next to the allylic radical center by reaction with $\mathrm{O}_{2}$. This has led us to revise the way of deriving from experimental results the corresponding rate constants : A equal to $2.3 \times 10^{11} \mathrm{~cm}^{3} \cdot \mathrm{mol}^{-1} \cdot \mathrm{s}^{-1}$ for the abstraction of a primary $\mathrm{H}$-atom, A equal to $7.9 \times 10^{11} \mathrm{~cm}^{3} \cdot \mathrm{mol}^{-1} \cdot \mathrm{s}^{-1}$ for the abstraction of a secondary $\mathrm{H}$-atom, E equal to $65 \mathrm{~kJ} / \mathrm{mol}$.

\section{Acknowledgements}

This work has been supported by the ADEME, PSA Peugeot Citroën, TOTAL and by the European Government within the "Safekinex” Project EVG1-CT-2002-00072. 


\section{REFERENCES}

[1] B. Heyberger, F. Battin-Leclerc, V. Warth, R. Fournet, G.M. Côme, G. Scacchi, Combust. Flame, 126 (2001) 1780-1802.

[2] B. Heyberger, N. Belmekki, V. Conraud, P.A. Glaude, R. Fournet, F. Battin-Leclerc, Int. J. Chem. Kin., 36 (2002) 666-677.

[3] (a) M. Ribaucour, R. Minetti, L.R. Sochet, Proc. Combust. Inst., 27 (1998) 345-351.

(b) R. Minetti, A. Roubaud, E. Therssen, M. Ribaucour, L.R. Sochet, Combust. Flame, 118 (1999) 213-220.

[4] S.P. Prabhu, R.K. Bhat, D.L. Miller, D.L., N.P. Cernansky, Combust. Flame, 104 (1996) 377-390.

[5] G. Vanhove, M. Carlier, R. Minetti, European Combustion Meeting (2003).

[6] V. Warth, N. Stef, P.A. Glaude, F. Battin-Leclerc, G. Scacchi, G.M. Côme, Combust. Flame, 114 (1998) 81-102.

[7] Battin-Leclerc, F., R. Fournet, P.A. Glaude, B. Judenherc, V. Warth, G.M. Côme, G. Scacchi, Proc. Combust. Inst., 28 (2000) 1597-1605.

[8] P.A. Glaude, V. Conraud, R. Fournet, F. Battin-Leclerc, G.M. Côme, G. Scacchi, P. Dagaut, M. Cathonnet, Energ.\&Fuels, 16 (2002) 1186-1195.

[9] P. Barbé, F. Battin-Leclerc, G.M. Côme, J. Chim. Phys., 92 (1995) 1666-1692.

[10] R.J. Kee, F.M. Rupley, J.A Miller, Sandia Laboratories Report, SAND 89 - 8009B (1993). 
[11] C. Muller, V. Michel, G. Scacchi, G.M. Côme, J. Chim.Phys., 92 (1995) 1154-1178.

[12] S.W Benson, Thermochemical Kinetics, 2nd ed., John Wiley, New York (1976).

[13] V. Bloch-Michel, Thèse de l'I.N.P.L., Nancy (1995).

[14] C. Richard, G. Scacchi, M.H. Back, Int. J. Chem. Kin., 10 (1978) 307-324.

[15] R.R. Baldwin, R.W. Walker, Proc. Combust. Inst., 18 (1980) 819-829.

[16] D. Perrin, C. Richard, R. Martin, Int. J. Chem. Kin., 20 (1988) 621.

[17] A. Mioyoshi, H. Masui, N. Washida, J. Phys. Chem., 94 (1990) 3016 -3019.

[18] T. Gierczak, J. Gawlowski, J. Niedzielski, Int. J. Chem. Kin., 18 (1986) 623-637.

[19] R.D. Wilk, B.P. Cernansky, W.J. Pitz, C.K Westbrook, Combust. Flame, 77 (1989) 145170.

[20] C.H. Wood, M. Sci. Thesis, Drexel University, Philadelphia (1994).

[21] M.S. Stark, D.J. Waddington, Int. J. Chem. Kin., 27 (1995) 123-151. 
TABLE 1 : Experimental and computed selectivity of products for the oxidation of 1-pentene in a rapid compression machine ( $\%$ molar), at $\mathrm{T}=733 \mathrm{~K}, \mathrm{P}=6.9$ bar for $20 \%$ conversion of 1-pentene in the conditions of fig. $3[3 \mathrm{~b}]$.

\section{Experiments Simulation}

Primary products

\begin{tabular}{lcc}
\hline & 3.9 & 7.0 \\
1,3-Pentadiene & 2.7 & 1.5 \\
2-Propyloxirane & 0.4 & 0.1 \\
2,4-Dimethyl-oxetane & 0.2 & 0.4 \\
2-Methyl-tetrahydrofurane & \\
$\begin{array}{l}\text { Cyclic ethers with an } \\
\text { alcohol function }\end{array}$ & - & 4.2 \\
$\begin{array}{l}\text { Unsaturated cyclic ethers } \\
\text { Cyclopentene }\end{array}$ & - & 20.2 \\
& $0.4^{\mathrm{a}}$ & 0.4 \\
\hline
\end{tabular}

Secondary products

\begin{tabular}{lcc}
\hline 1,3-Butadiene & 3.9 & 3.0 \\
2-butenal & $0.8^{\mathrm{a}}$ & 3.3 \\
Acroleïne & 13.0 & 8.5 \\
Butanal & 7.4 & 2.1 \\
Propanal & 0.8 & 0.3 \\
Ethanal & 29.6 & 22.2 \\
Formaldehyde & - & 36.1 \\
Ethylene & $25.2^{\mathrm{a}}$ & 17.7 \\
Carbon monoxide & $64.1^{\mathrm{a}}$ & 23.5 \\
& & \\
\hline \multicolumn{2}{c}{ a $:$ unpublished results } &
\end{tabular}




\section{FIGURE CAPTIONS}

Figure 1: Algorithm of generation for the primary mechanism of the oxidation of small alkenes.

Figure 2 : Consumption of propene versus residence time at 626,678 and $715 \mathrm{~K}$ in a static reactor for an equivalence ratio equal to 0.8 and a pressure of $79 \mathrm{kPa}$ [19].

Figure 3 : Cool flame and auto-ignition delays of 1-pentene in a rapid compression machine [3]. Bold lines are obtained with the full mechanism and simple lines with a mechanism, in which the rate constants of some types of reactions have been multiplied by a factor 10 , as described in the text.

Figure 4 : Consumption of 1-pentene in plug flow reactor [4, 20].

Figure 5 : Auto-ignition delays of 1-hexene in a rapid compression machine [5].

Figure 6 : Flow rate analysis for the oxidation of 1-pentene at $800 \mathrm{~K}$ in the conditions of Fig. 3 just before the cool flame. White arrows and products written in italic are relevant to the secondary mechanism. 
Figure 1

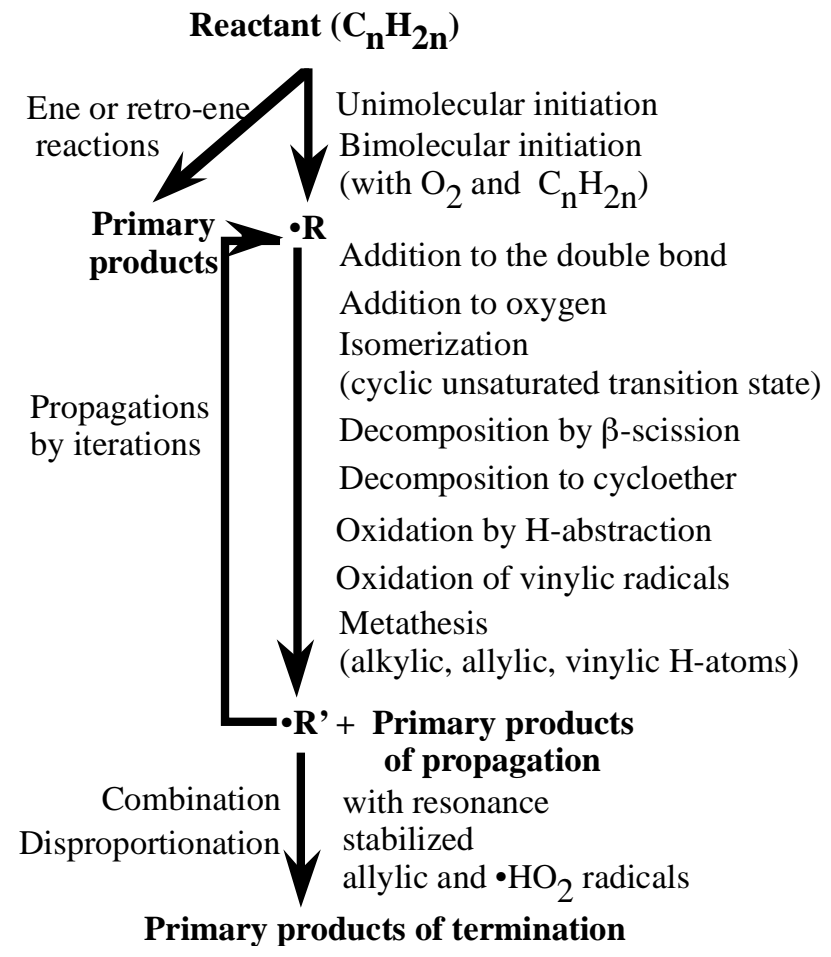


Figure 2

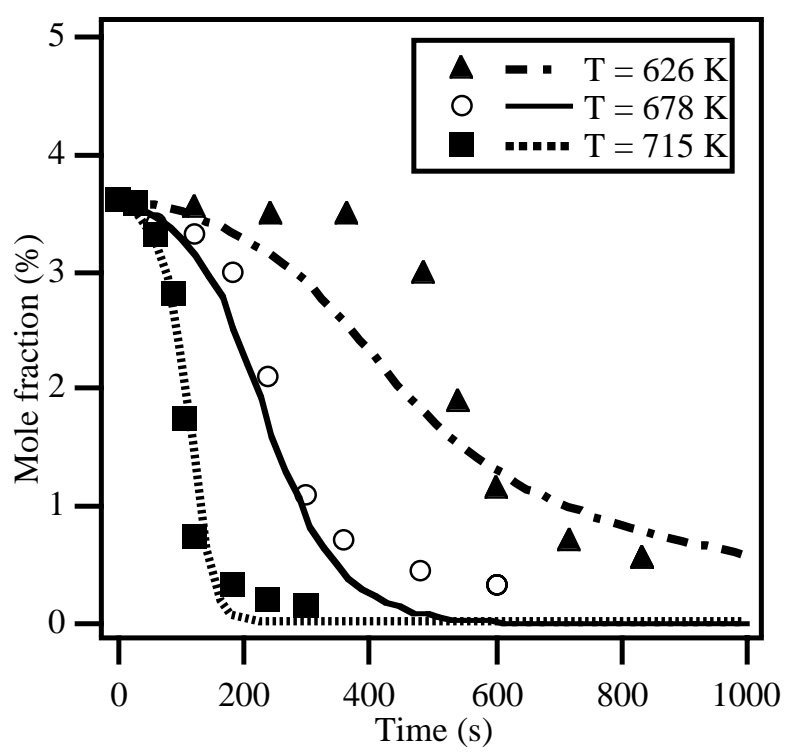


Figure 3

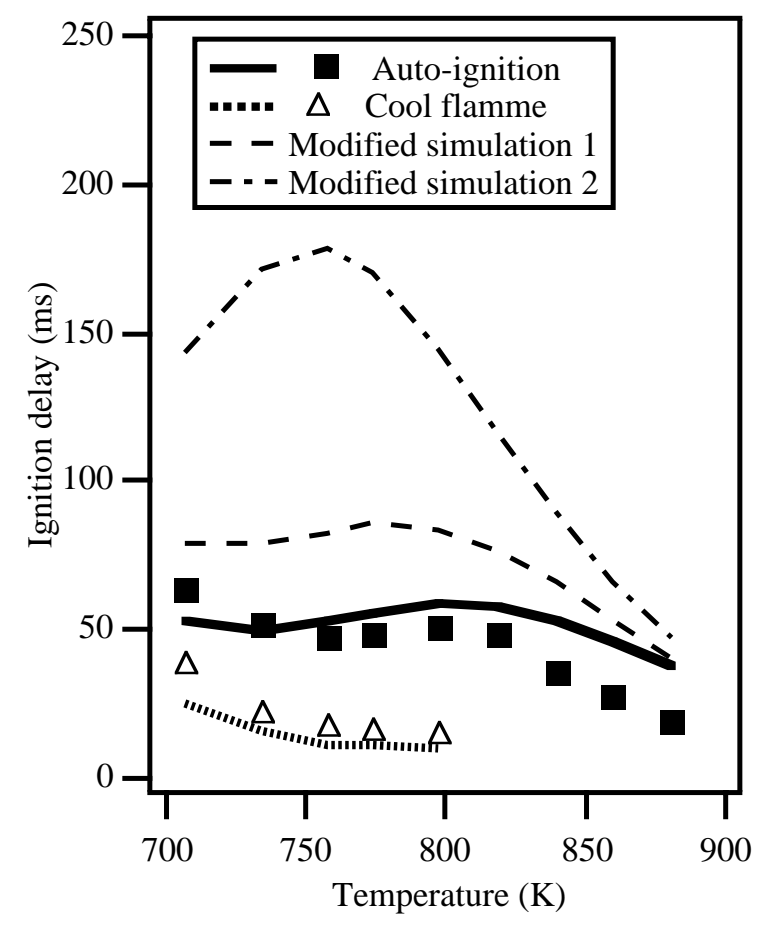


Figure 4

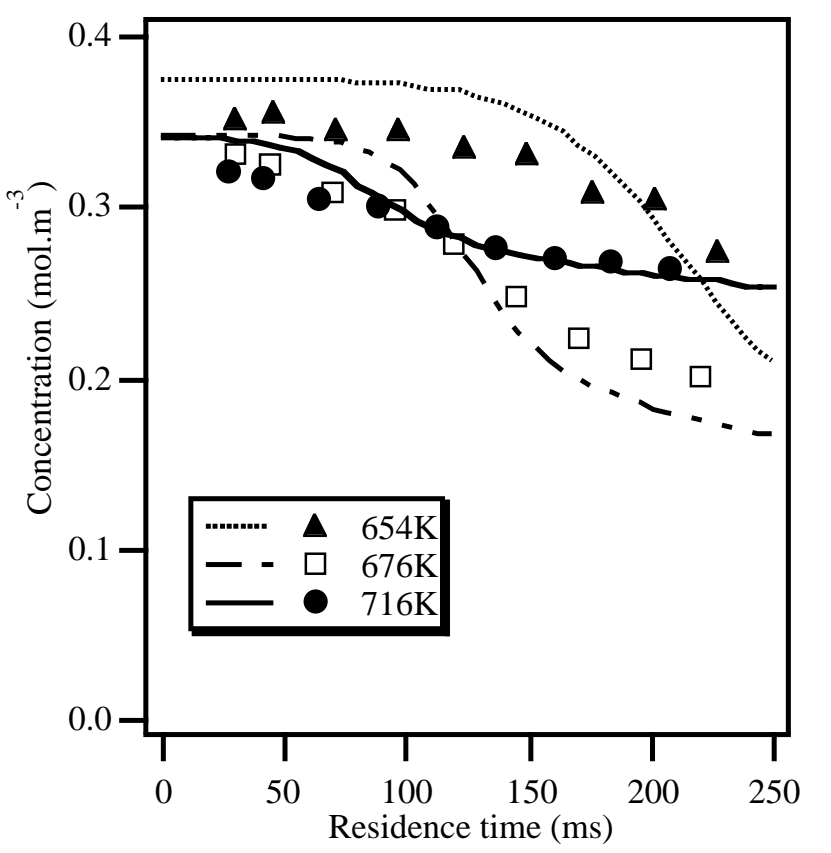


Figure 5

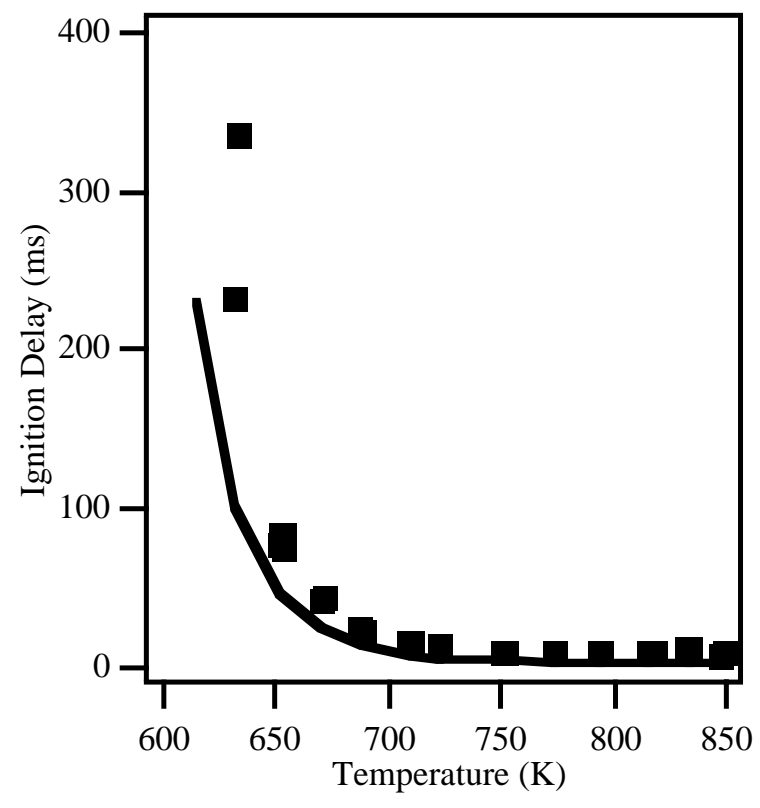




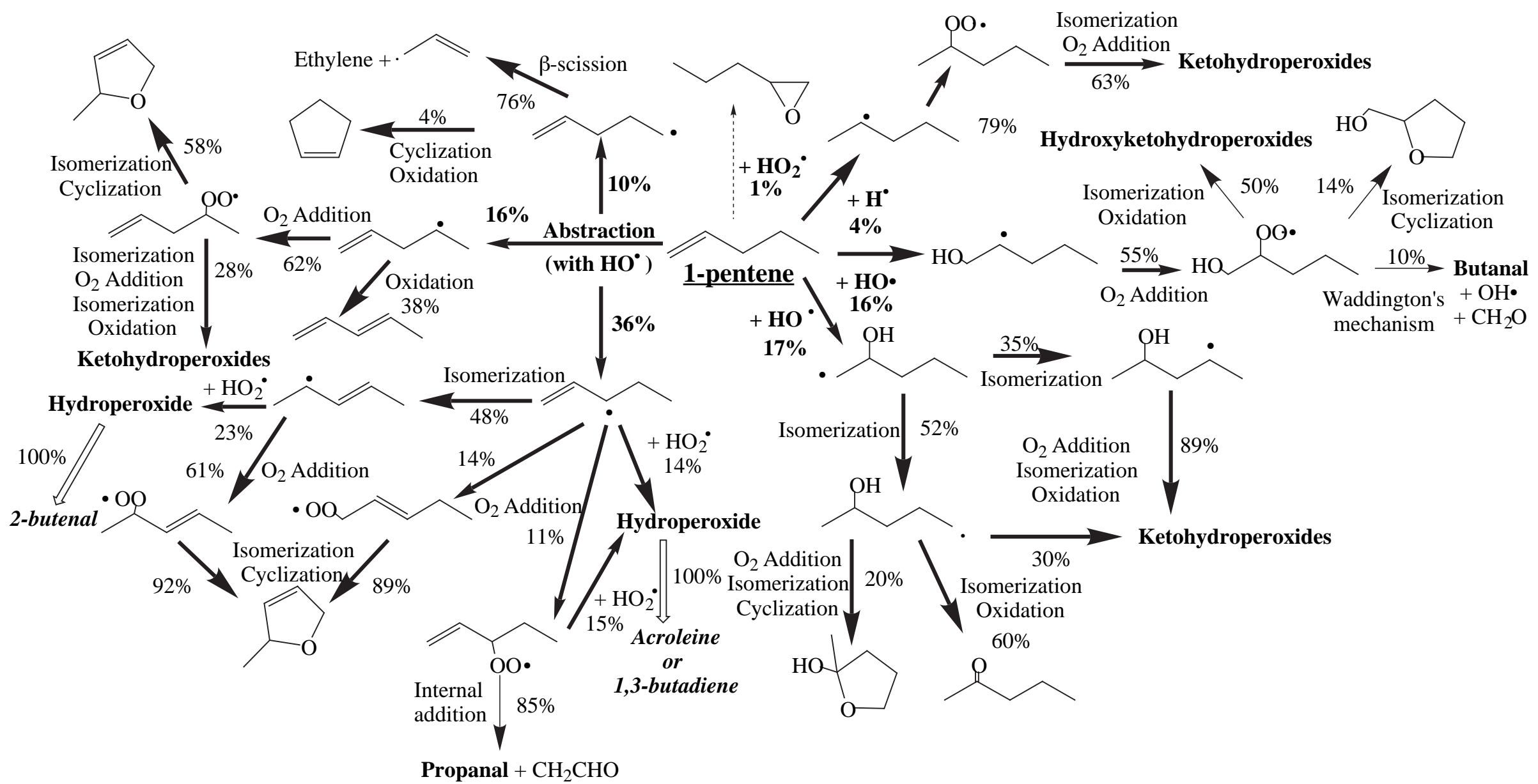

